\title{
Dental Surface Disorder
}

National Cancer Institute

\section{Source}

National Cancer Institute. Dental Surface Disorder. NCI Thesaurus. Code C35597.

A disorder that affects the surface of the tooth. 